\title{
JRCICE2007-40064
}

\section{PERFORMANCE EFFICIENCY OF A CRASH ENERGY MANAGEMENT SYSTEM}

\author{
Michael Carolan \\ David Tyrell \\ Volpe National Transportation Systems Center \\ U.S. Department of Transportation \\ Cambridge, MA 02142
}

\author{
A. Benjamin Perlman \\ Tufts University \\ Department of Mechanical Engineering \\ Medford, MA 02155
}

\section{ABSTRACT}

Previous work has led to the development of a crash energy management (CEM) system designed to distribute crush throughout unoccupied areas of a passenger train in a collision event. This CEM system is comprised of crush zones at the front and rear ends of passenger railcars. With a consist made up of CEM-equipped cars, the structural crush due to a collision can be distributed along the length of the train, crushing only unoccupied areas and improving the train's crashworthy speed as compared with a conventional train in a similar collision.

This paper examines the effectiveness of one particular CEM system design for passenger rail cars. The operating parameters of the individual components of the CEM system are varied, and this paper analyzes the effects of these variations on the behavior of the consist during a collision. The intention is to determine what modifications to the components, if any, could improve the crashworthiness of passenger railcars beyond the baseline CEM design without introducing new hazards to passengers.

A one-dimensional, lumped-mass model of a passenger train impacting a heavy freight train was used in this investigation. Using this model of a collision, the force-crush behavior for each end of each car in the impacting consist was varied. The same force-crush characteristic was applied to each car end on the passenger train.

The four components of the CEM system investigated were the draft gear, pushback coupler, primary energy absorbers, and occupied volume of the train car. The paper presents selected parameters of particular interest, such as the strength ratio of the primary energy absorber to the pushback coupler and the average strength of the occupied volume.

The objective of this work was to ascertain the sensitivities of the various parameters on the crashworthy speed and to help optimize the force-crush characteristic. This investigation determined that modifications could be made to the baseline characteristic to improve the train's crashworthy speed without creating new hazards to occupants.

\section{INTRODUCTION}

The Federal Railroad Administration (FRA) has been conducting research on passenger rail crashworthiness for a number of years. This research has included crash testing of conventional rail vehicles $[1,2,3]$, as well as the design, construction, and crash testing of prototypical crash energy management (CEM) vehicles $[4,5,6]$. This testing program has been designed to understand the behavior of passenger rail equipment in collision events so that strategies can be proposed to increase the safety of passengers involved in a rail collision. Since full-scale testing of railroad vehicles is costly, accurate computer models of both vehicle and passenger behaviors are desirable to simulate how rail vehicles will respond in various collision scenarios. Accurate models are also necessary to design further full-scale tests.

In a collision involving a conventionally constructed passenger train, the front end of the colliding car is generally subject to the largest amount of structural crush, with a resulting loss of passenger volume [1]. An alternative strategy for passenger railroad crashworthiness, known as CEM, has been developed to improve the safety of passenger railcars. The CEM system relies on strategically placed crush zones to absorb the collision energy. With a consist made up of CEM-equipped cars, the structural crush can be distributed along the length of the train, preferentially crushing unoccupied areas of the individual railcars.

\section{Background}

North American passenger cars are designed with a stiff, strong underframe to prevent the occupied volume from crushing. Figure 1 shows a schematic plan view of a typical underframe construction in a conventional car [7]. The draft sill 
and center sill are large structural members designed to carry the majority of the longitudinal load. Once the draft gear has loaded to the point of bottoming out, the forces are transmitted through the buff lugs and into the underframe structure.

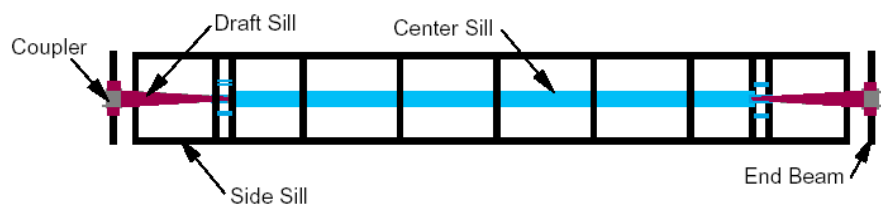

Figure 1. Conventional Underframe Structure

Recent crashworthiness research included full-scale crash testing of conventional railroad equipment [1,2,3]. Based on the data collected from this testing, the idealized force-crush characteristic of Figure 2 shows the basic crush behavior. The first segment of the characteristic corresponds to the draft gear on the car's front end engaging and bottoming out. The steep slope following this corresponds to the draft sill's loading with force and, at the peak, failing in some mode of buckling. Once the draft sill has failed, the rest of the car structure cannot resist the force that is applied, thus crushing at a relatively low level of force. The 5 feet of the characteristic seen in Figure 2 come from actual test measurements, while the force-crush characteristic beyond this area is extrapolated.

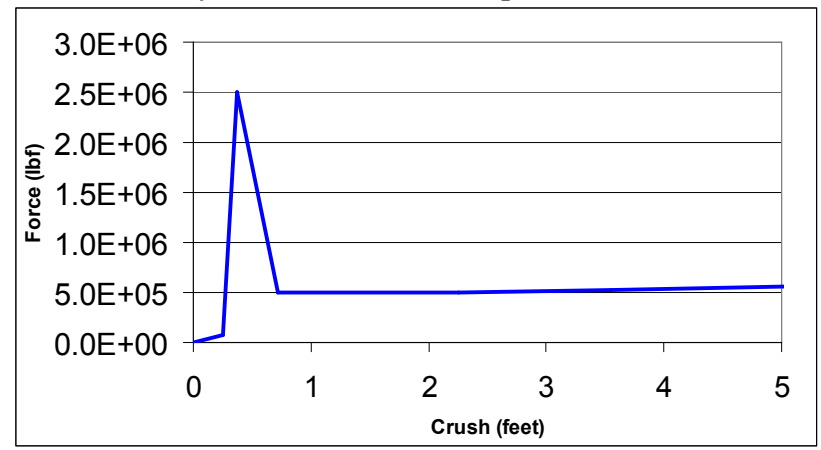

Figure 2. Conventional Force-Crush Characteristic

CEM systems increase the crashworthiness of passenger cars by allowing for crush in a controlled, progressive manner. Conventional cars are built to a uniform stiffness and, thus, crush occupied and non-occupied areas of the car indiscriminately. CEM rail cars are designed to crush in nonoccupied areas while maintaining the occupied volume. The crash energy is absorbed by crush zones distributed throughout the consist, rather than just by the front end of the impacting car.

Figure 3 shows a diagram taken from a finite element model of the prototype CEM system. In a collision event, the draft gear will bottom out, and the pushback coupler will activate. This device is designed to function as a typical coupler during regular service and be compatible with conventional cars with conventional couplers. The bolts holding the coupler in place are designed to fail in shear if a critical load is exceeded. Once over this activation level, the coupler crushes an aluminum honeycomb energy absorber.

Once the pushback coupler has triggered and exhausted its energy-absorbing capabilities, force is transferred to shear bolts on the sliding sill structure. These bolts also fail at a prescribed level, transferring load to the primary energy absorbers. After exhausting the primary energy absorbers, the structure of the passenger compartment is loaded. Less is known about the specifics of crush behavior in this region, as no full-scale CEM crash tests have been run with speed sufficient to exceed the capabilities of the CEM system.

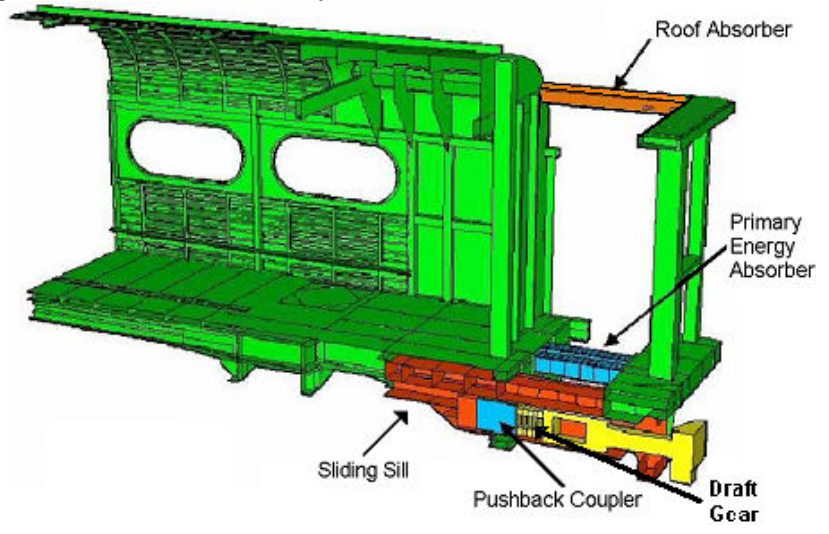

Figure 3. Finite Element Model of Coach Car CEM System Design

Figure 4 shows the baseline CEM force-crush characteristic studied in this research, which is adapted from the force-crush characteristic developed in Reference 4. This characteristic features segments corresponding to four distinct components included in this design: the draft gear, pushback coupler, primary energy absorber, and occupied volume.

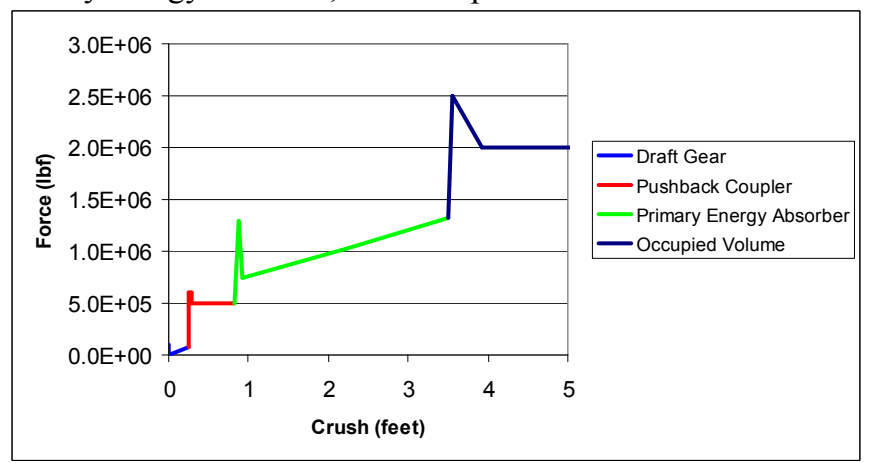

Figure 4. Baseline CEM Force-Crush Characteristic

In both conventional and CEM cars, crushing the first 3.5 feet of car will not result in passenger fatalities, as the areas are assumed to be unoccupied vestibules. Taking the areas underneath the force-crush characteristics shown above, it is apparent from Figure 5 that the CEM car can absorb more energy than the conventional car over this distance. In 3.5 feet of crush, the CEM car absorbs 4.2 MJ (3.1 x $\left.10^{6} \mathrm{ft}-\mathrm{lbf}\right)$ of energy while the conventional car absorbs only $2.9 \mathrm{MJ}(2.1 \mathrm{x}$ $10^{6} \mathrm{ft}-\mathrm{lbf}$ ) of energy in the same distance. 


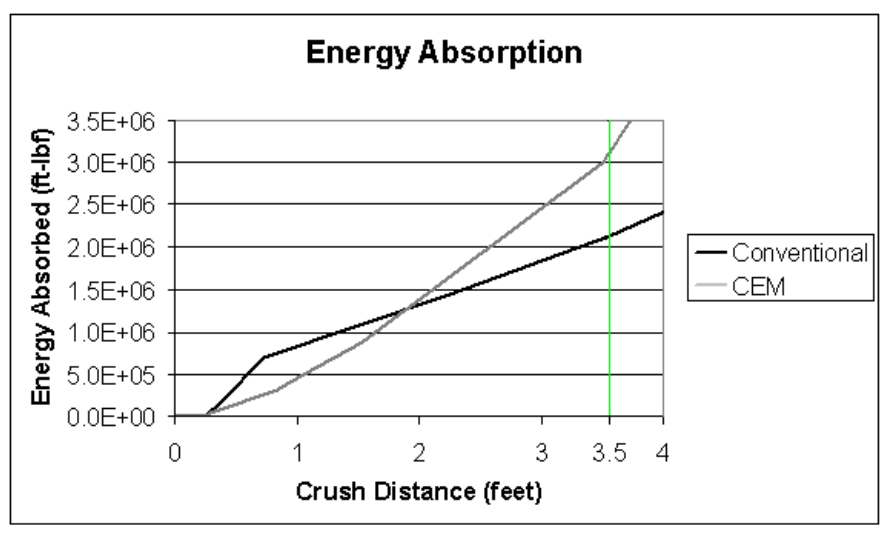

Figure 5. Energy Absorption of Conventional and CEM Cars

As shown in Figure 5, the conventional car absorbs more energy for crush distances less than approximately 2 feet. This amount of crush would correspond to a low-speed collision. In a conventional car, crushing the first 2 feet corresponds to crushing the draft gear and crippling the draft sill. In the CEM car, the first 2 feet include the draft gear, pushback coupler, and a portion of the primary energy absorbers. The CEM system is designed to crush in a controlled, progressive manner at any collision speed. The conventional design, however, is subject to large-scale deformation of the structural members that can lead to ramp formation and potential override of coupled cars.

Figure 6 shows the distribution of crush among car ends for two $30 \mathrm{mph}$ collisions. In each collision, a cab car-led passenger train with a trailing locomotive impacted an initially stationary heavy freight train. The distribution on the top is from a simulation using the conventional characteristic in Figure 2. The crush is focused on the leading end of the impact cab car.

The distribution on the bottom of Figure 6 is from a train made up of cars with the CEM characteristic shown in Figure 4. This collision has crush distributed among the trailing crush zones. In an ideal CEM system, the crush would be equal at all car ends. In the system evaluated in this paper, crush does not occur evenly at all interfaces. Typically, one crush zone in a coupled interface will activate before the other. The crush zone that activates first will have more total crush on it than the crush zone it is coupled to.

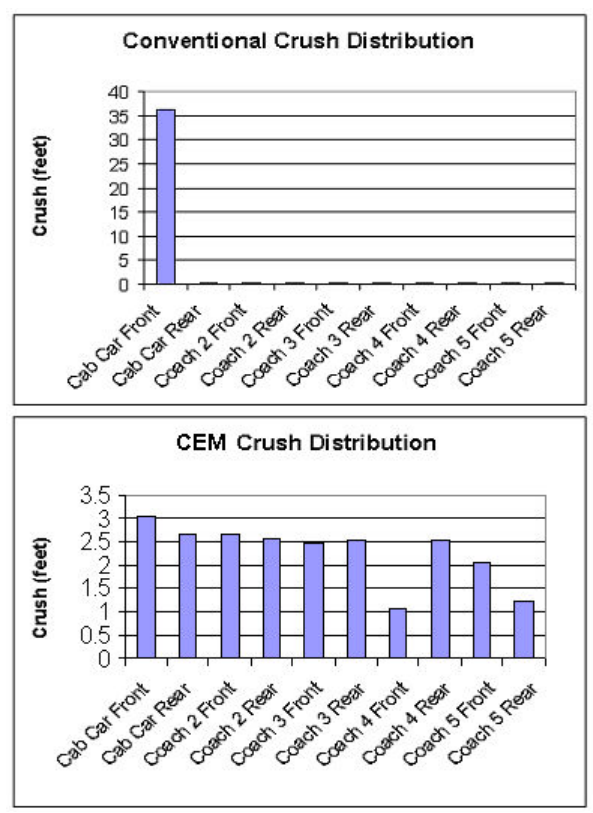

Figure 6. Crush Distribution for a $30 \mathrm{mph}$ Collision

\section{RESEARCH APPROACH}

Through a series of full-scale crash tests, the prototype CEM system has been shown to improve the passenger safety of railcars over the conventional design. In order to examine the efficiency of this system, various modifications were systematically made to the baseline characteristic, and this modified characteristic was then run in a simulation of a train collision. The operating parameters of the individual components of the CEM system were varied, and the effects of these variations were examined. The ultimate goal is to determine what modifications to the components, if any, could be made to the baseline force-crush characteristic to improve the crashworthiness of passenger railcars without introducing new hazards to passengers.

\section{Modeling Details}

This study uses a one-dimensional, lumped-mass model of a passenger train impacting a freight train. This model, created in MSC.ADAMS [8], is built upon models previously created by the Volpe Center [7]. The passenger cars are linked to one another via rigid connectors that do not contribute to the energy absorption of the cars. The freight cars and freight locomotive each contain linear springs with a constant of $1.2 \times 10^{7} \mathrm{lb} / \mathrm{ft}$. These springs are designed to absorb little energy and represent the stiff structure present in the freight locomotive and cars. Figure 7 shows example cars typical of both freight and passenger cars in this simulation. 


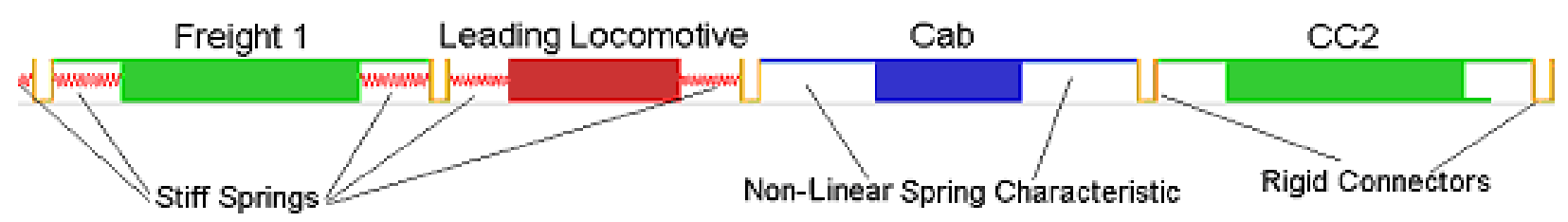

Figure 7. Lumped-Mass Model of Train-to-Train Collision

The collision scenario chosen was an initially moving passenger train impacting an initially standing freight train. This scenario represents a severe collision case, as the passenger train will have to dissipate the entirety of the crash energy. This behavior implies that at any given speed studied in this research, the resulting collision between the passenger consist and another similar passenger consist will be less severe than cases seen in this research, as the impacted passenger consist will have more energy-absorbing capacity than the freight consist studied.

The initially standing freight train was composed of a locomotive and five trailing cars. Table 1 shows the weights of the individual cars. The freight train was allowed to move in the longitudinal direction following the impact, with a coefficient of friction of 0.2 simulating the train's braking. The passenger train was a cab car-leading train made up of five passenger cars and a trailing locomotive. Table 1 shows the weights of the cars. The weights of the passenger cars were chosen to be similar to the weights of the cars in the train-totrain test of CEM equipment conducted in March 2006 [6].

Table 1. Car Weights Used in Lumped-Mass Model

\begin{tabular}{|cc|cc|}
\hline \multicolumn{2}{|c|}{ Freight Consist } & Passenger Consist \\
Car Name & $\begin{array}{c}\text { Weight } \\
\text { (kips) }\end{array}$ & Car Name & $\begin{array}{c}\text { Weight } \\
\text { (kips) }\end{array}$ \\
Leading Loco. & 263 & Cab & 75 \\
Freight 1 & 181 & CC2 & 75 \\
Freight 2 & 181 & CC3 & 75 \\
Freight 3 & 181 & CC4 & 75 \\
Freight 4 & 181 & CC5 & 75 \\
Heavy Freight & $11403^{*}$ & Trailing Loco & 263 \\
*Simulates 63 & & & \\
additional freight cars & & & \\
\hline
\end{tabular}

\section{METHODOLOGY}

This research examined the regions of the force-crush characteristics associated with specific CEM system components: the draft gear, pushback coupler, and primary energy absorbers. In addition, the strength of the occupied volume of the car after the exhaustion of the CEM system was examined. Table 2 shows the parameters examined for each component.
Table 2. Components and Parameters Examined

\begin{tabular}{|c|c|}
\hline Component & Parameters Examined \\
\hline \multirow{4}{*}{ Draft Gear } & Stroke Length \\
\cline { 2 - 2 } & Slope of Operating Force \\
\hline \multirow{4}{*}{ Pushback Coupler } & Peak Activation Force \\
\cline { 2 - 2 } & Average Operating Force \\
\cline { 2 - 2 } & Slope of Operating Force \\
\hline \multirow{4}{*}{ Primary Energy } & Stroke Length \\
\cline { 2 - 2 } Absorber & Peak Activation Force \\
\cline { 2 - 2 } & Average Operating Force \\
\cline { 2 - 2 } & Slope of Operating Force \\
\cline { 2 - 2 } & Stroke Length \\
\cline { 2 - 2 } & Ratio of PEA Average Level to PBC Average Level \\
\hline \multirow{2}{*}{ Occupied Volume } & Peak Activation Force \\
\cline { 2 - 2 } & Average Strength of Car \\
\hline
\end{tabular}

For a given component, the target parameter being studied was varied while the rest of the force-crush characteristic was held at its baseline value. The value of the parameter being investigated was varied over a reasonable range, typically above and below the baseline value. The collision simulation was run over a range of 5-50 $\mathrm{mph}$ in $5 \mathrm{mph}$ increments. The highest speed at which no car end crushed into the occupied volume portion of the force-crush characteristic was determined to be the train's crashworthy speed for that given value of the given parameter. The simulation was run in $1 \mathrm{mph}$ increments near the crashworthy speed.

\section{Measures of Performance}

In order to determine the crashworthiness of a particular CEM system design at a given closing speed, this study considered two factors that contribute to serious injuries and fatalities: the amount of occupied volume crushed and the secondary impact velocity (SIV) experienced by the passengers. These two measures provided an idea of the collision's severity on the car body and the severity of the interior environment passengers would encounter.

\section{Occupied Volume Crush}

The occupied volume crush measurement was determined for each car end in the train at each speed being tested. While 
the front end of the cab car typically underwent the most deformation, certain cases existed where trailing cars experienced a greater amount of crush than the front end of the cab car. It was assumed that the car could crush up to the peak of the occupied volume strength without incurring any fatalities, as this area is assumed to be unoccupied. On the baseline curve, this amounts to a distance of 3.5 feet. As the lengths of certain components were altered in the course of the research, the acceptable crush distance was altered as well.

In the baseline case, the crashworthy speed is $36 \mathrm{mph}$. Because of the uneven distribution of crush on the car ends, the total energy absorption capacity of the CEM system is not exhausted at this speed. The interfaces farther back in the consist are still capable of absorbing more energy, though the leading end of the cab car has exceeded its own energy capacity and compromised the occupied volume.

This research does not seek to define an absolute crashworthy speed at which occupied volume will be preserved. Rather, this work investigates the factors that have the largest influence on the crashworthy speed. This work uses the range of crashworthy speeds obtained by varying the value of a particular parameter to determine the sensitivity of the crashworthy speed to the value of that parameter.

\section{SIV}

A primary impact occurs when a moving consist strikes an object on the tracks. Since passengers within the train are unrestrained, at the instant the train car begins to decelerate they will be in free flight. The secondary impact occurs when these passengers strike an interior fixture of the car, such as the seat ahead of them. SIV is the passenger's velocity relative to the car when the secondary collision occurs. SIV is calculated from the acceleration-time history of a given car's center of gravity. Integrating this data once with respect to time gives the relative velocity, and integrating twice gives the displacement used in the SIV. In the case where a passenger consist is impacting a massive freight train, it is possible for the cab car to rebound after impact and travel in the opposite direction. This can lead to SIVs that are above the closing speed of the collision, as the passenger is traveling forward while the car is traveling backward.

For the purposes of this research, it is assumed that an unrestrained passenger will impact the seatback ahead of him or her after traveling a distance of 2 feet. This distance is a typical distance between a passenger's head and the seatback of the row ahead on many commuter trains. This value is not an absolute standard in revenue service; alternate configurations may include workstation tables or open bay (face-to-face) seating options [9].

The severity of the injuries a passenger is likely to sustain is assumed to be proportional to the SIV when the passenger strikes part of the car's interior. Previous work has been conducted to correlate the severity of injury to the head, chest, and neck with the SIV experienced in a collision [9]. The SIV is dependent on the closing speed of the train, the distance between the passenger and the object he/she strikes, and the deceleration behavior of the car under investigation. In the conventional and CEM trains, the cab car is subjected to the most severe deceleration upon impact with the standing freight train. Therefore, the SIV will be highest for passengers in this car, and this value of SIV sets the limiting speed for this factor.

The SIV and the design of the train's interior determine the appropriate level of occupant protection needed during a collision. Figure 8, which has been adapted from a graphic in [9], exemplifies the increasingly active levels of occupant protection necessary to minimize fatalities sustained in a collision, given the SIV at a particular distance. As the passenger impacts the car's interior at a higher speed, it becomes necessary to employ more advanced restraint and protection systems to minimize passenger injury. Passive safety measures include steps undertaken in the design of the vehicle's interior, such as rounded corners and seats designed to deform in a controlled manner, which will minimize the fatalities sustained in a collision.

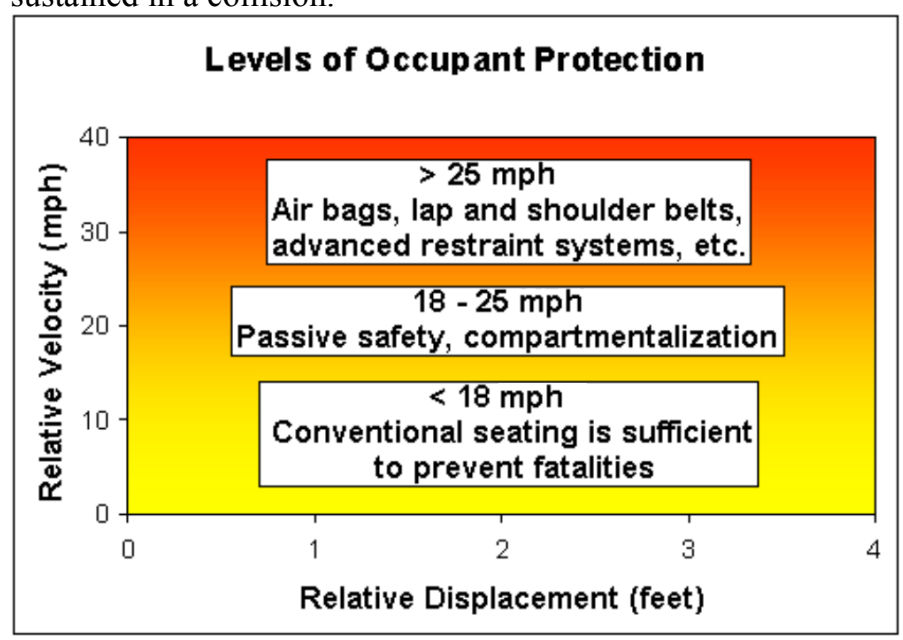

Figure 8. Levels of Occupant Protection

Using the baseline CEM force-crush characteristic and a 30 mph closing speed, the baseline SIV at a distance of 2 feet was found to be approximately $23 \mathrm{mph}$. This speed falls into the middle range, where passive safety measures and passenger compartmentalization are appropriate strategies to protect the occupants in the event of a collision.

\section{RESULTS}

As shown in Table 2, a significant number of parameters were investigated as part of this research. These parameters had varying degrees of influence on the consist's overall behavior over the ranges of parameters examined. Table 3 shows the relative significance of each parameter examined. This paper presents those results that had the most significant effects on crashworthy speed, SIV, and the velocity-time histories of the passenger cars. A more complete listing of the results for all parameters can be found in [10]. 
Table 3. Relative Significance of Parameters

\begin{tabular}{|c||c|c|c|}
\hline Draft Gear & Lost Significant & Moderate & Least Significant \\
\cline { 2 - 4 } Pushback Coupler & Average Force & Stroke Length & $\begin{array}{c}\text { Slope } \\
\text { Trigger Force }\end{array}$ \\
\hline $\begin{array}{c}\text { Primary Energy } \\
\text { Absorber }\end{array}$ & Strength Ratio & $\begin{array}{c}\text { Average Force } \\
\text { Slope } \\
\text { Stroke Length }\end{array}$ & \\
\hline Occupied Volume & Car Strength & & Trigger Force \\
\hline
\end{tabular}

As an extension of the results discussed below, multiple varied parameters were combined to form a new force-crush characteristic. The ranking of relative significance provided an indication of which parameters would be most useful in creating a characteristic with desirable behaviors.

\section{Primary Energy Absorber}

The ratio of the average level of the primary energy absorber to the pushback coupler can be altered a number of ways: changing the force level of the pushback coupler, changing the average force of the primary energy absorber, or a combination of the two. In previous work, an investigation into the strength ratio between primary energy absorber and pushback coupler was conducted [11]. In this prior research, the strength ratio was altered by modifying the level of the pushback coupler while the primary energy absorber level was held constant. The total amount of energy absorbed by the CEM system was allowed to vary with the level of the coupler. That research demonstrated that with an increased strength ratio, the crashworthy speed also increased.

The current investigation maintained the total amount of energy absorbed by the CEM system at $3.1 \times 10^{6} \mathrm{ft}-\mathrm{lbf}$. The strength ratio was varied by maintaining the level of the pushback coupler at its baseline value $(500,000 \mathrm{lbf})$ and altering the average strength of the primary energy absorbers. In order to maintain the same amount of energy absorbed by the system, the length of the primary energy absorbers was altered along with the level of the absorbers. The baseline length of the primary energy absorber was approximately 31 inches, over which the primary energy absorber had an average force of $1,000,000 \mathrm{lbf}$. This gave a baseline primary energy absorber to pushback coupler (PEA:PBC) strength ratio of 2.0. Figure 9 shows two sample force-crush characteristics with different PEA:PBC ratios.

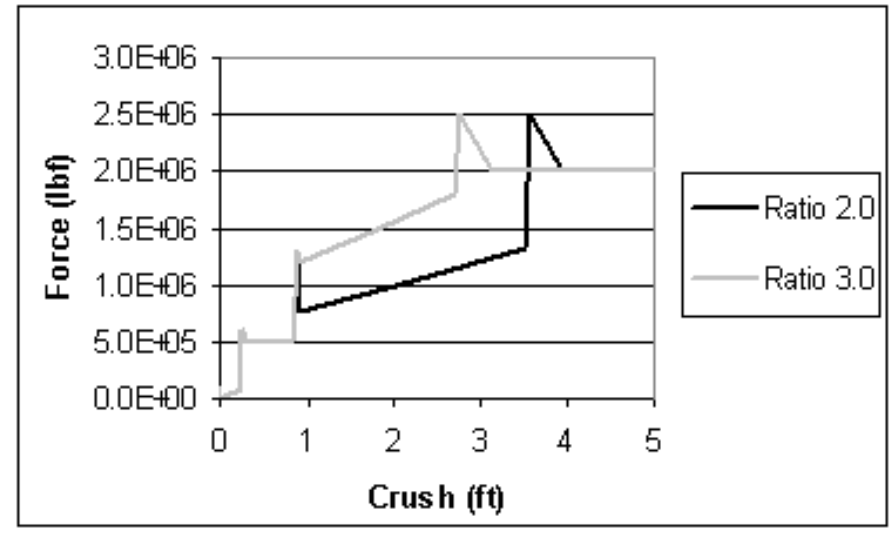

Figure 9. Comparison of PEA:PBC Ratios

By increasing the strength ratio between the primary energy absorber and the pushback coupler, the crush on the car can be more evenly distributed. Figure 10 shows the crush distribution after a $30 \mathrm{mph}$ collision on a train with a ratio of 2.0 and one with a ratio of 3.0. The ratio of 2.0 represents the baseline case. By further increasing this ratio to 3.0 , the crush can be distributed more evenly throughout the consist, taking advantage of more of the energy-absorbing capacity of each car end.
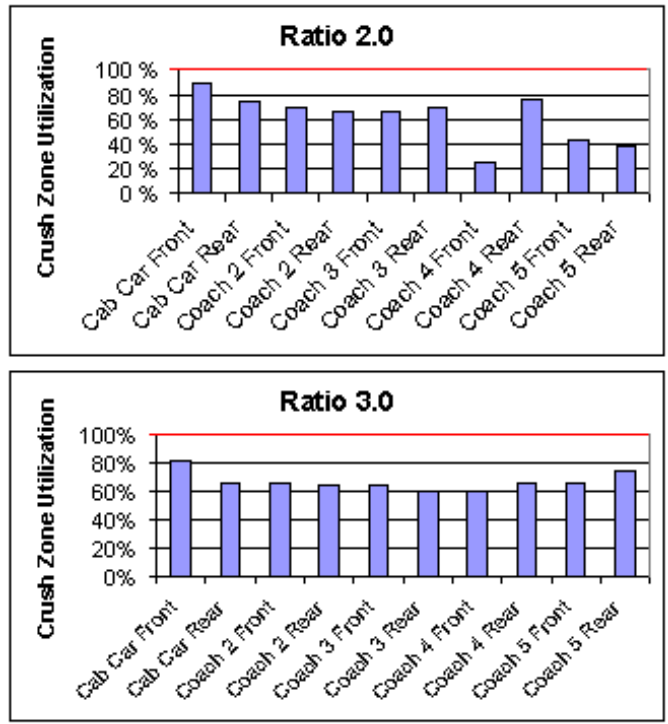

Figure 10. Crush Distribution for Varied Ratios

In the case where the ratio is 2.0 , the cab car sustains the most damage, crushing nearly 90 percent of its available crush zone. When the ratio is increased to 3.0, the cab car is still the most severely crushed area. The maximum amount of crush is now limited to 80 percent of the available crush zone. Since the kinetic energy at impact and total energy absorption capability of both trains are held constant, the crush that no longer takes place at the cab car front end must be re-distributed among the trailing cars in the consist. Figure 10 shows that the higher ratio case has a more even distribution of crush among the intermediate car ends than the lower ratio case. 
This result demonstrates that attention must be paid not only to the system's total energy capacity, but the manner in which that energy is absorbed throughout the consist. The system's energy capacity was maintained at a constant level throughout this investigation, with the difference being the stroke length and average force of the primary energy absorbers. In order to get a more efficient distribution of crush and increase the crashworthy speed, the strength ratio should be increased.

This uneven distribution of crush affects the safe speed of the consist. Since the lower ratio cases feature an inability to evenly distribute crush, the energy absorption capabilities of the front cars are exhausted at a lower speed. By increasing the ratio, even without increasing the system's total energy capacity, the crush can be distributed more evenly and exhaustion of one individual crush zone will occur at a higher speed. Figure 11 shows the crashworthy speed for each ratio, demonstrating that the crashworthy speed increases with increasing ratio between the two components.

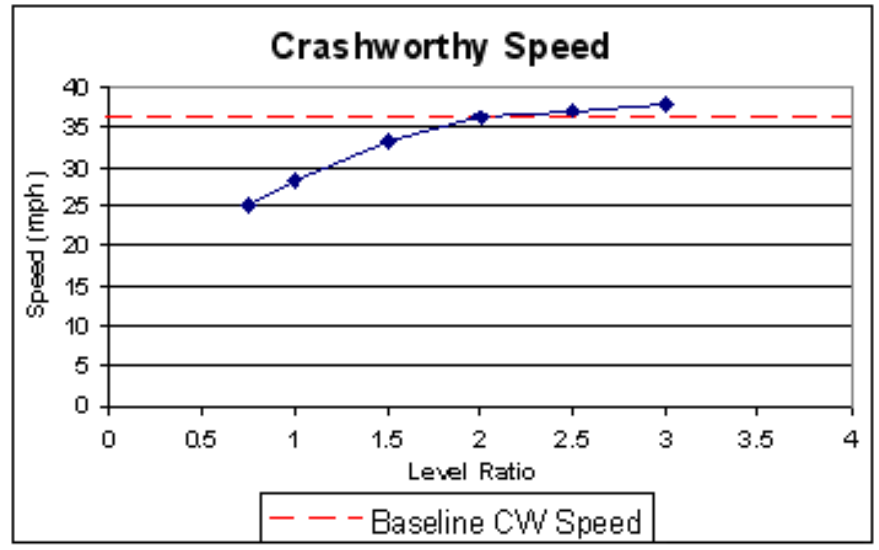

Figure 11. Crashworthy Speed for Varied PEA:PBC Ratios

The baseline crashworthy speed is $36 \mathrm{mph}$. The lowest crashworthy speed, $25 \mathrm{mph}$, is found at a ratio of 0.75 , and the highest crashworthy speed of $38 \mathrm{mph}$ is found at a ratio of 3.0. This variance of $13 \mathrm{mph}$ indicates that the crashworthy speed is sensitive to the strength ratio between the average level of the primary energy absorber and the level of the pushback coupler. In particular, the crashworthy speed is more dramatically affected by decreasing the ratio than it is by increasing it. The maximum crashworthy speed is $2 \mathrm{mph}$ greater than the baseline case, while the minimum speed is $11 \mathrm{mph}$ lower than the baseline case.

Figure 12 shows a plot of the SIV for the cab car at each PEA:PBC ratio. As the PEA:PBC level ratio increases, the SIV up until 2 feet also increases. Since an increased ratio means a higher level of force acting over a decreased stroke length, the deceleration experienced by the occupants of the cab car will be more severe than for a low-level force acting over a longer stroke. For any ratios greater than the baseline ratio of 2.0, the SIV at 2 feet exceeds $25 \mathrm{mph}$. At this level, more aggressive occupant protection strategies are appropriate to reduce the likelihood of fatalities due to striking interior fixtures [Figure 8].

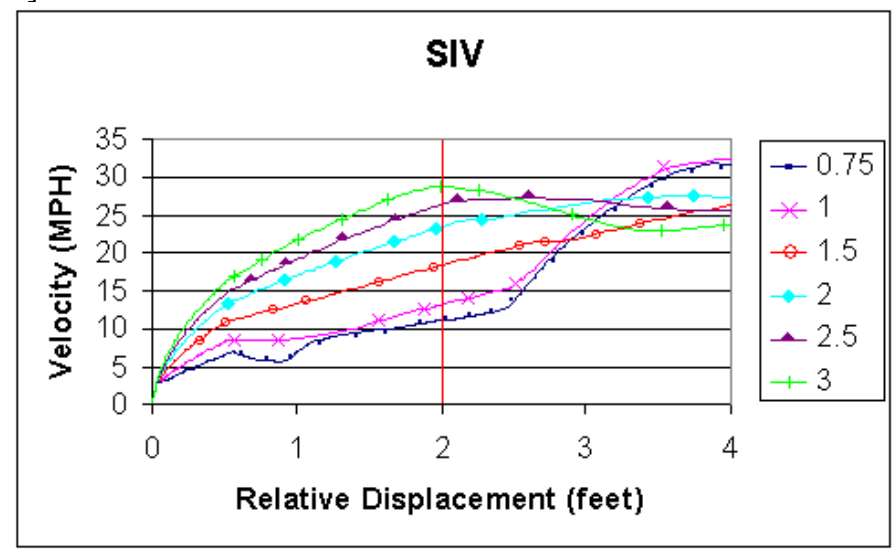

Figure 12. SIV for Varied PEA:PBC Strength Ratios

By increasing the ratio between the average level of the primary energy absorber and the pushback coupler level, the crashworthy speed can be increased with the tradeoff of an increased SIV. It is possible, through interior modifications, to lessen the severity of the secondary impact environment and decrease the total number of fatalities expected in a given collision. It is assumed that fatalities caused by loss of occupied volume cannot be prevented. If a CEM system with a ratio greater than 2.0 were to be implemented on a railcar, it would be necessary to perform modifications to the car's interior in order to lessen the expected number of fatalities caused by secondary impact injuries.

\section{Occupied Volume Strength}

Although it is not a part of the CEM system, the structure of the car body is considered in this investigation for its effects on the behavior of the consist during a collision event. For the CEM system to be at all effective, a sufficiently strong occupied volume structure is necessary. While the CEM system is designed to absorb crush in order to preserve the occupied volume, it is within the realm of possibility that a collision will occur at a speed such that the energy absorption capabilities of the CEM system are exhausted and crush proceeds into the occupied volume. It is desirable that the CEM system will continue to distribute crush throughout the consist, even if the occupied volume is not preserved on every car. The CEM system should never perform worse than the conventional coach design under similar impact conditions.

Research into the occupied volume is more difficult to compare to known behavior, as no CEM full-scale crash testing has taken place with significant closing speed to exceed the capacity of the CEM system. Additionally, data from conventional testing has been difficult to interpret with certainty, as the crush in this region of the car is uncontrolled and has been accompanied by motion in the vertical and lateral directions. The research presented in this paper seeks to determine the parameters of the car body strength that will 
provide the most effective use of CEM after the system has been exhausted on at least one car end.

After the CEM system has been exhausted, the draft sill begins to load and, with sufficient force, will fail. Once this large peak load has been exceeded, the body of the car crushes with a near-uniform strength along the length of the car. Figure 13 shows this behavior for two car body strength values. The car body must have a static buff strength of at least 800,000 lbf, as per FRA regulations (See 49 C.F.R. 238.203 [12]). In the baseline force-crush characteristic, the car body will crush with a force of 2,000,000 lbf after the force overcomes a 2,500,000 lbf peak. The crashworthy speed of the consist is not affected by the post-peak car body strength, as the crashworthy speed must be exceeded in order to crush the car body in the first place. The crashworthy speed remains at $36 \mathrm{mph}$ for all levels of car body strength.

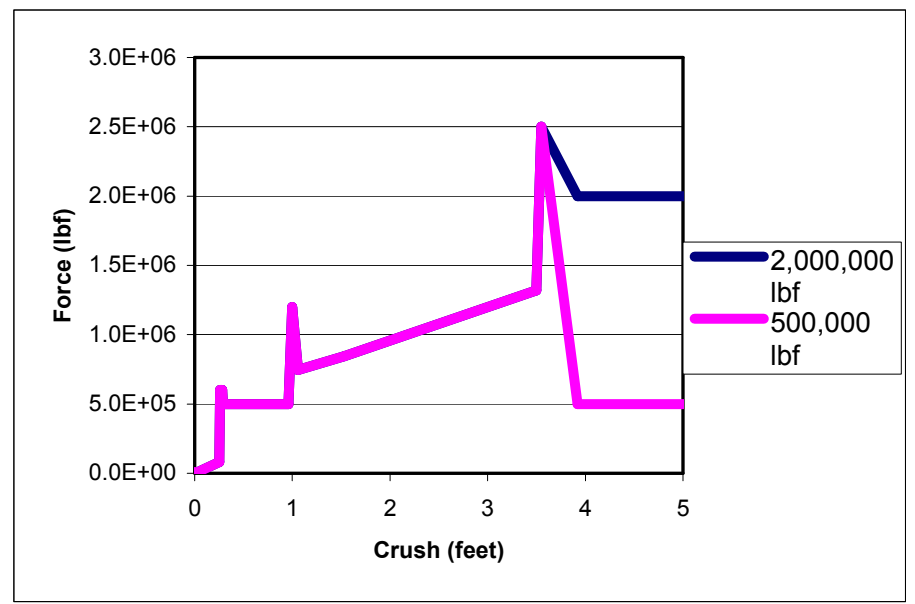

Figure 13. Occupied Volume Strength Variation

Because the total energy absorbed by the CEM system only considers crush of the draft gear, pushback coupler, and primary energy absorbers, altering the force-crush characteristic in the car body strength region does not affect the energy-absorbing capacity of the CEM system. The strength level of the car body was varied as low as 500,000 lbf and as high as 4,000,000 lbf. This post-peak car body strength assumes the peak value of the car body strength is sufficiently large that the car is capable of meeting the $800,000 \mathrm{lbf}$ buff strength requirement.

The crush distribution of a $40 \mathrm{mph}$ collision in a CEM train with a body strength of only 500,000 lbf [Figure 14] is similar to the crush distribution of a conventional train in a similar collision scenario [Figure 6]. This occurs because the body strength is insufficient to pass crush back to the trailing cars. The train has sufficient energy to exhaust the CEM system on the front end of the cab car and begin crushing the occupied volume of the car. Because the body crushes at a low strength in this car, the force necessary to engage and exhaust subsequent CEM car ends is not able to build up, and crushing is concentrated on the impacting end of the cab car.

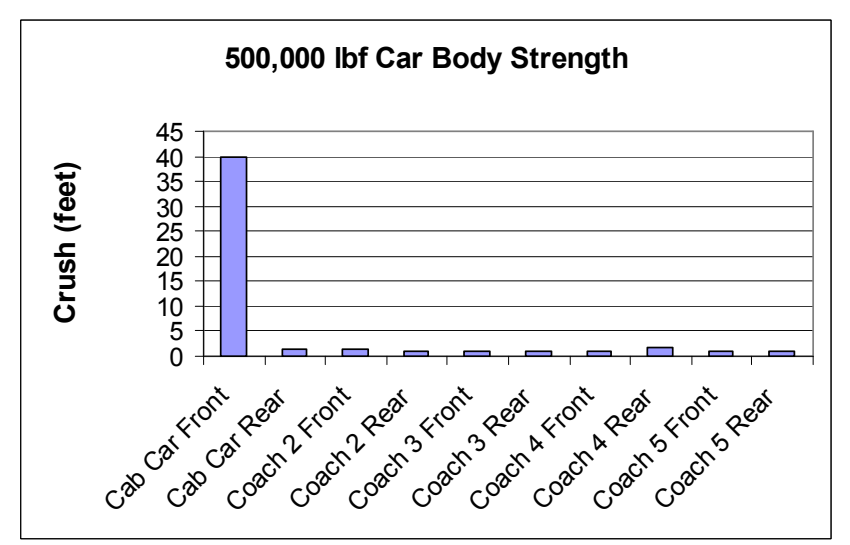

Figure 14. Crush Distribution for a $40 \mathrm{mph}$ Collision

Strengthening the car body results in less concentration of crush on the impacting end of the cab car. Figure 15 shows the amount of crush on the front end of the cab for each car body strength level. In each case, the closing speed of the train was $40 \mathrm{mph}$. The amount of crush decreases dramatically with each increase in strength between 500,000 and 1,250,000 lbf. Increasing the strength beyond 1,250,000 $\mathrm{lbf}$ will still decrease the amount of crush occurring on the impacting end of the cab car but not as dramatically.

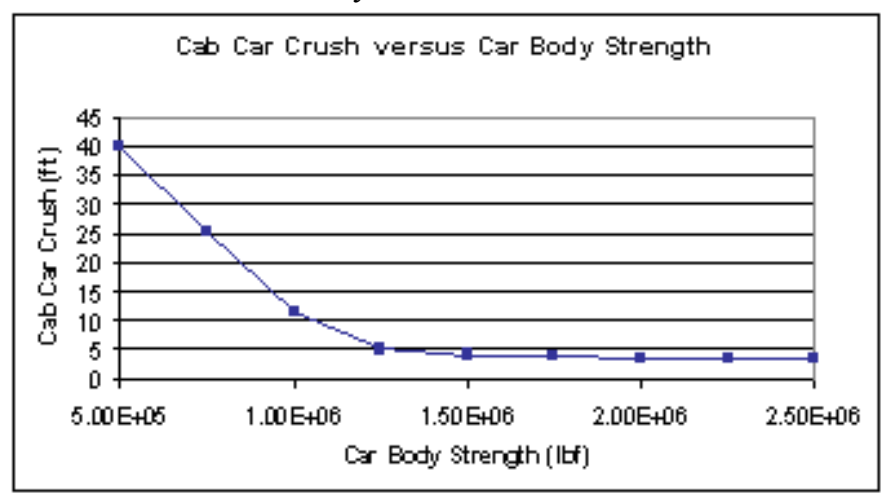

Figure 15. Cab Car Crush for $40 \mathrm{mph}$ Collisions

In order to see benefits from the CEM system at speeds above the crashworthy speed, the strength of the car must exceed 1,250,000 million lbf. While varying the strength of the car body does not affect the speed at which the occupied volume is compromised, the degree of volume lost is greatly affected by decreasing the car body strength. At its lowest strength, the cab car body crushes 40 feet; at its highest value, 3.75 feet of cab car front end are lost. The number of fatalities caused by loss of occupant volume will be much greater in the case where 40 feet of car body are crushed as compared to the case where 3.75 feet are crushed. While the crush from a higher strength car will be distributed to the other cars in the consist and cause some of them to crush into their occupied volumes, the total amount of occupied volume lost will still be less than the cases where the crush is concentrated on the front end of the cab car. 
The rapid deceleration that is a result of the increased car body strength results in an increased SIV for passengers seated in the cab car. As Figure 16 shows, the SIV becomes greater as car body strength is increased. The SIV curves are identical for displacements less than approximately 1.5 feet because the CEM force-crush characteristic is identical up until the car body strength. The SIV curves shown in Figure 16 are for a $40 \mathrm{mph}$ closing speed, as that speed is sufficient to intrude into occupied volume at any level of the car body strength. SIV curves presented in previous sections of this paper were for a $30 \mathrm{mph}$ closing speed.

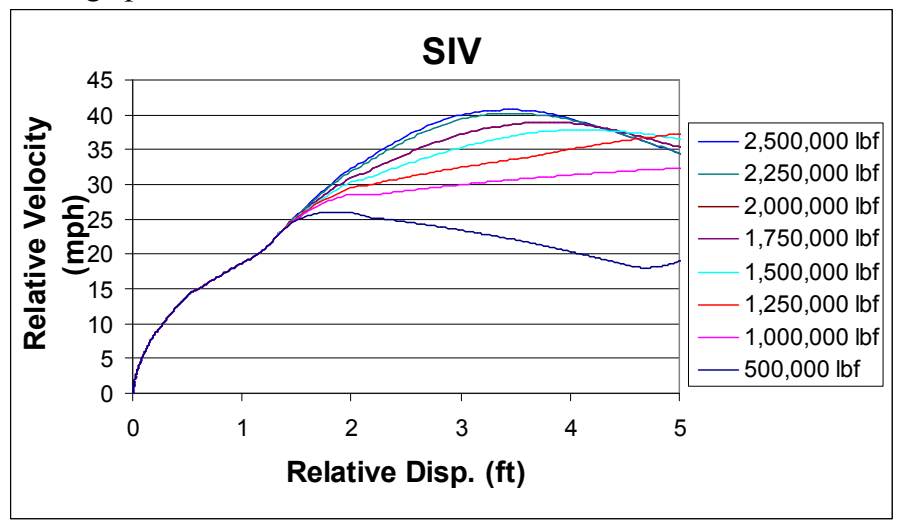

Figure 16. SIV for $40 \mathrm{mph}$ Collision, Varied Car Body Strength

While decreasing the strength of the car will cause a decreased SIV, it will also cause an increase in the loss of occupied volume. Particularly, if the strength is decreased below 1,250,000 lbf, the loss of occupied volume becomes much greater for each 250,000 lbf the strength is decreased. The greater likelihood of injury corresponding to an increased SIV can be mitigated through the use of more aggressive occupant protection strategies [Figure 8]. The injuries and fatalities caused by a loss of occupied volume cannot be mitigated by interior modifications.

\section{EXTENSION OF RESEARCH RESULTS}

Once the effects of individual parameters had been investigated, multiple parameters were varied within the same force-crush characteristic. The parameters that were varied encompassed all of the parameters investigated in this research, not just those with the most significant effects. The purpose of these simulations was to determine what, if any, improvements could be made to the baseline force-crush characteristic to improve the crashworthy speed and the SIV conditions at the same time.

Specific restrictions were applied to the modifications that could to be made to the force-crush characteristic. The distance the car was allowed to crush before loading the occupied volume was chosen in the baseline case to allow simple modification of existing passenger cars to CEM passenger cars. The baseline characteristic does not require the removal of any occupied volume to integrate a CEM system; thus car capacity is unaffected. The CEM passenger cars are also limited in size to be compatible with existing tracks, stations, and coupled equipment. Because of these restrictions, the maximum amount of crush before loading the occupied volume is limited to 3.5 feet. This distance includes the stroke of the draft gear, the stroke of the pushback coupler, and the length of the primary energy absorbers.

The research examined five modified force-crush characteristics. The two criteria examined to determine the improvement over the baseline force-crush characteristic are the crashworthy speed and the SIV. In particular, the SIV of an occupant in the cab car during a $30 \mathrm{mph}$ impact was recorded after a 2-foot relative displacement. Figure 17 shows a plot of the five modified force-crush characteristics, as well as the baseline force-crush characteristic. The complete descriptions of the modifications made to the baseline can be found in [10].

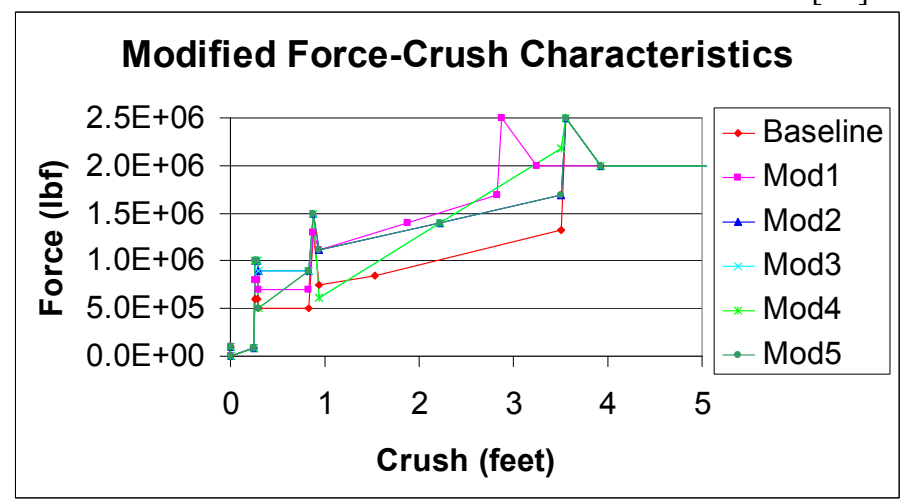

Figure 17. Modified Force-Crush Characteristics

Figure 18 shows the SIV plots for each of the modified force-crush characteristics. The closing speed for the collisions was $30 \mathrm{mph}$. Modification 2 features a higher SIV than the baseline force-crush characteristic for displacements less than 2 feet and smaller SIVs for displacements greater than 2 feet. Modification 3 features a lower-than-baseline SIV for displacements less than approximately 2.5 feet and greater than 4 feet.

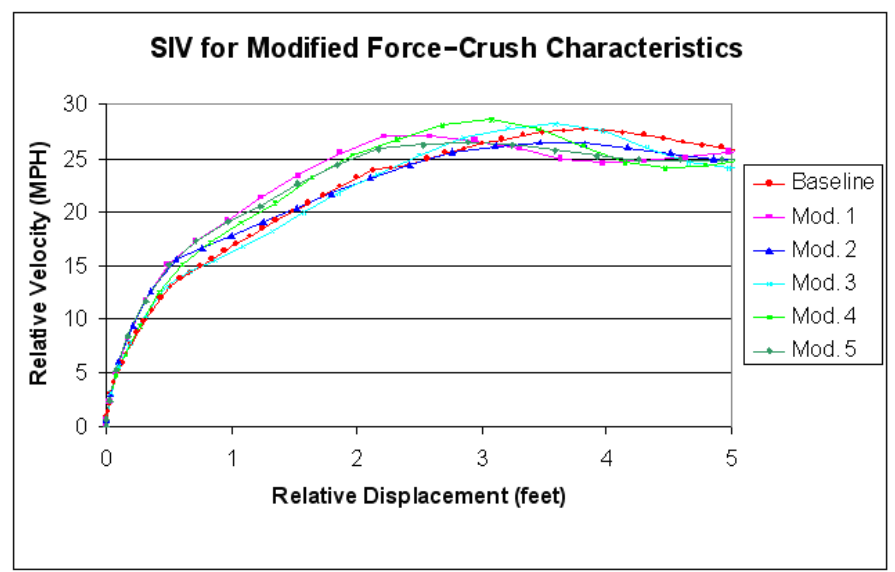

Figure 18. SIV for Modified Force-Crush Characteristics 
Table 4 shows the results for crashworthy speed and SIV at a displacement of 2 feet. Two modified characteristics improved upon both the crashworthy speed and SIV conditions from the baseline characteristic. While these values should not be taken as absolute safe speeds, they do provide an idea of the effect that the modified characteristic will have upon the behavior of the consist. Modification 2 and Modification 3 provide a crashworthy speed that is greater than the baseline crashworthy speed without increasing the examined SIV.

Table 4. Modified Force-Crush Characteristic Results

\begin{tabular}{|c|c|c|}
\hline $\begin{array}{c}\text { Force-Crush } \\
\text { Characteristic }\end{array}$ & $\begin{array}{c}\text { Crashmorthy } \\
\text { Speed (mph) }\end{array}$ & SIV (mph) \\
\hline Baseline Characteristid & 36 & 23.13 \\
\hline Modification 1 & 38 & 26.17 \\
\hline Modificaion 2 & 39 & 22.65 \\
\hline Modification 3 & 41 & 22.44 \\
\hline Modification 4 & 43 & 25.49 \\
\hline Modification 5 & 40 & 25.25 \\
\hline
\end{tabular}

These results are not all encompassing. The intention of this investigation was to demonstrate that while the baseline force-crush characteristic is effective as designed, it is possible to increase the effectiveness of the CEM system and thus the crashworthy speed of the train, without increasing the hazards from secondary impacts. Further investigations are necessary to determine additional modifications that can be made to the baseline force-crush characteristic in this manner.

\section{SUMMARY AND CONCLUSIONS}

The research described in this paper is based on the consist of CEM cars tested in the 2006 train-to-train test [6]. The weights of the cars and the baseline force-crush characteristic were chosen to simulate this particular CEM system. To conduct the test, the end vestibules were removed from each car and replaced by the CEM components. This situation is not the only arrangement possible for a CEM system. Alternate car configurations must be designed to ensure the crush of the CEM system takes place in unoccupied areas of the car. Additionally, service factors such as numbers of cars, weight, or multiple-unit equipment should be taken into account. One study of the effects of these parameters on CEM system performance [11] has been reported previously.

This research examined the effects of altering individual portions of the baseline force-crush characteristic to represent different parameters designed into the individual components of the CEM system. The research also determined the relative level of influence that the value of each parameter had over the behavior of the consist during a collision event.

The strength ratio between the primary energy absorber and the pushback coupler was altered in such a way that the total energy absorbed by the CEM system was kept constant throughout the investigation. As the ratio between the two components was increased, the crush distributed more evenly throughout the car ends in the consist. This distribution increases the crashworthy speed of the train. By increasing the PEA:PBC ratio, the SIV at a distance of 2 feet is also increased. This tradeoff in safety aspects can be mitigated through more active methods of interior crashworthiness.

The strength of the car body after its peak strength has been exceeded was investigated for its effect on the behavior of a CEM train involved in a collision that exceeds the energy capacity of the CEM system as designed. The train's crashworthy speed is not affected by this parameter; by definition crushing of the occupied volume indicates that the crashworthy speed has been exceeded. The amount of crush on the cab car for a given closing speed will decrease with increased car body strength. The SIV of an occupant in the cab car striking the interior at a distance of 2 feet will increase as the car body strength increases.

This study demonstrated that the baseline CEM force-crush characteristic was effective in decreasing the number of anticipated fatalities when compared to the conventional passenger rail car design. Through manipulation of the parameters examined in this research, it is also possible to increase the crashworthiness of passenger trains beyond the baseline CEM system.

\section{ACKNOWLEDGEMENTS}

This work was performed as part of the Equipment Safety Research Program sponsored by the FRA Office of Research and Development. The authors thank Eloy Martinez, Program Manager, and Claire Orth, Division Chief, Equipment and Operating Practices Research Division, Office of Research and Development, FRA, for their support.

\section{REFERENCES}

1. Tyrell, D., "Passenger Rail Train-to-Train Impact Test Volume I: Overview and Selected Results," DOT/FRA/ORD03/17.1, U.S. Department of Transportation, Washington, DC, July 2003.

2. Tyrell, D., Severson, K., Perlman, A.B., "Single Passenger Rail Car Impact Test Volume I: Overview and Selected Results," U.S. Department of Transportation, DOT/FRA/ORD00/02.I, March 2000.

3. Tyrell, D., Severson, K., Zolock, J., Perlman, A.B., "Passenger Rail Two-Car Impact Test Volume I: Overview and Selected Results," U.S. Department of Transportation, DOT/FRA/ORD-01/22.I, January 2002.

4. Jacobsen, K., Tyrell, D., Perlman, A.B., "Impact Test of a Crash-Energy Management Passenger Rail Car," American Society of Mechanical Engineers, Paper No. RTD2004-66045, April 2004.

5. Severson, K., Parent, D., Tyrell, D., "Two-Car Impact Test of Crash Energy Management Passenger Rail Cars: Analysis of Occupant Protection Measurements," American Society of 
Mechanical Engineers, Paper No. IMECE2004-61249, November 2004.

6. Tyrell, D., Jacobsen, K., Perlman, A.B., "Train-to-Train Impact Test of Crash Energy Management Passenger Rail Equipment: Structural Results," American Society of Mechanical Engineers, Paper No. IMECE2006-13597, November 2006.

7. Severson, K.J, "The Development of Collision Dynamics Models to Estimate the Results of Full-Scale Rail Vehicle Impact Tests," Tufts University Master's Thesis, November 2000.

8. MSC.ADAMS 2003, MSC.Software Corporation, Ann Arbor, Michigan.

9. Parent, D., "Session I: Overview of CEM Interior Crashworthiness," Crash Energy Management Technology Transfer Symposium, June 29-July 1, 2005, San Francisco, California, Session I.

10. Carolan, M., "Performance Efficiency of Crash Energy Management Systems," Tufts University Undergraduate Honors Thesis, May 2006.

11. Priante, M., "Influence of Train Parameters on Crashworthiness Performance of Passenger Trains," Tufts University Undergraduate Honors Thesis, May 2004.

12. U.S. Department of Transportation, Federal Railroad Administration, "49 CFR Part 216 et al., Passenger Equipment Safety Standards; Final Rule,” Federal Register, May 12, 1999. 